\title{
Magnesium Deficiency and Gastric Bypass
}

\author{
Joel Faintuch
}

Published online: 29 March 2011

(C) Springer Science+Business Media, LLC 2011

\section{Dear Editor,}

We appreciate the interest of Arvo Haenni, MD, Ph.D., for our study [1], particularly involving the outcome of magnesium. It is correct that magnesium was deficient before surgery, and it can be gleaned from our preoperative findings that a similar phenomenon occurred with vitamin B12, folic acid, and iron, just to mention the most conspicuous. This is no novelty and multiple deficiencies have been robustly demonstrated before [2-4], in bariatric candidates.

Another reason preoperative abnormalities and especially hypomagnesemia were not addressed was the focus of the study on late follow-up. Patients received dietary counsel by the time of bariatric intervention, so relevance of previous aberrations for long-term outcome was deemed questionable.

Indeed, recovery of low values or stability of magnesium in case of adequate patterns is the rule during the first up to the second postoperative year, including the series coauthored by Haenni [5-7]. The contribution of our text concerned the possibility of hypomagnesemia both by 2 years and by 7-8 years, something much rarely announced.

We are grateful for pointing out the confusion regarding the study by Brolin and Leung. The references should be Halverson $[8,9]$.

Cordially, Joel Faintuch, MD, Ph.D.
Conflicts of Interest None.

\section{References}

1. Dalcanale L, Oliveira CPMS, Faintuch J, et al. Long-term nutritional outcome after gastric bypass. Obes Surg. 2010;20:181-7.

2. Kaidar-Person O, Person B, Szomstein S, et al. Nutritional deficiencies in morbidly obese patients: a new form of malnutrition? Part B: minerals. Obes Surg. 2008;18:1028-34.

3. Schweiger C, Weiss R, Berry E, et al. Nutritional deficiencies in bariatric surgery candidates. Obes Surg. 2010;20:193-7.

4. Flancbaum L, Belsley S, Drake V, et al. Preoperative nutritional status of patients undergoing Roux-en-Y gastric bypass for morbid obesity. J Gastrointest Surg. 2006;10:1033-7.

5. Coupaye M, Puchaux K, Bogard C, et al. Nutritional consequences of adjustable gastric banding and gastric bypass: a 1-year prospective study. Obes Surg. 2009;19:56-65.

6. Skroubis G, Anesidis S, Kehagias I, et al. Roux-en-Y gastric bypass versus a variant of biliopancreatic diversion in a nonsuperobese population: prospective comparison of the efficacy and the incidence of metabolic deficiencies. Obes Surg. 2006;16:488-95.

7. Johansson HE, Zethelius B, Ohrvall M, et al. Serum magnesium status after gastric bypass surgery in obesity. Obes Surg. 2009;19:1250-5.

8. Halverson D. Vitamin and mineral deficiencies following obesity surgery. Gastroenterol Clin North Am. 1987;16:307-15.

9. Halverson JD. Micronutrient deficiencies after gastric bypass for morbid obesity. Am Surg. 1986;52:594-8.

J. Faintuch $(\bowtie)$

Nutrition and Metabolism Program,

Hospital das Clinicas and Sao Paulo University Medical School,

Sao Paulo, Brazil

e-mail: jfaintuch@hcnet.usp.br 